\section{Arsenic release during oxidative dissolution of sulfide minerals under dynamic redox conditions in flow- through porous media}

\author{
MARIA BATTISTEL ${ }^{1}$, LUCIEN STOLZE ${ }^{1}$, MUHAMMAD \\ MUNIRUZZAMAN $^{2}$ AND MASSIMO ROLLE ${ }^{1}$
}

${ }^{1}$ Technical University of Denmark

${ }^{2}$ Geological Survey of Finland

Presenting Author: marbat@env.dtu.dk

The oxidative dissolution of As-bearing sulfide minerals is one of the major pathways of arsenic mobilization and it is of primary importance in systems where conditions are typically subject to spatial and temporal changes [1]. This study [2] investigates the kinetic oxidative dissolution of a natural Asbearing sulfide ore, composed by löllingite and arsenopyrite, under dynamic redox conditions. We performed 1-D and 2-D flow-through experiments in which the ore is embedded in different concentrations and spatial distributions into a sandy matrix. The systems are initially maintained under anoxic conditions and then an oxic solution is flushed into the setups, triggering the oxidative dissolution of the reactive minerals. The consumption of oxygen due to the oxidation of the minerals was monitored with a non-invasive high-resolution technique, that allowed us to capture the oxygen dynamic front during the experiments. The oxidation of löllingite and arsenopyrite also entails arsenic mobilization, as well as changes in pore water chemistry, surface-solution interactions and mineral precipitation. We developed a reactive transport model to quantitatively interpret the interplay between the primary Asbearing sulfide minerals, the dissolved products of the oxidative dissolution, and the secondary mineral phases. The outcomes of the simulation show that a freshly precipitated iron-arsenate phase reincorporates the $40 \%$ of the arsenic released by the dissolution of the reactive minerals and creates a coating on the surface of the reactive minerals limiting the dissolution reactions. The model also allows to shed light on the temporal and spatial dynamics of the arsenic release and transport in the flow-through setups. Different dissolution rates of the As-sulfide minerals result in an initially higher contribution of the fast dissolving löllingite to the total arsenic released, while the importance of arsenopyrite increases at late times, implying that a limited-size inclusion of As-bearing natural ore sustains high arsenic plumes for a long time. This is of particular importance if the As-source is composed of different minerals, whose different dissolution rates can cause a long-term release of arsenic and thus a longterm groundwater contamination.

[1] Lazareva et al. (2015) Appl. Geochemistry 52, 57-66.

[2] Battistel et al. (2021) J. Hazard. Mater. 124651

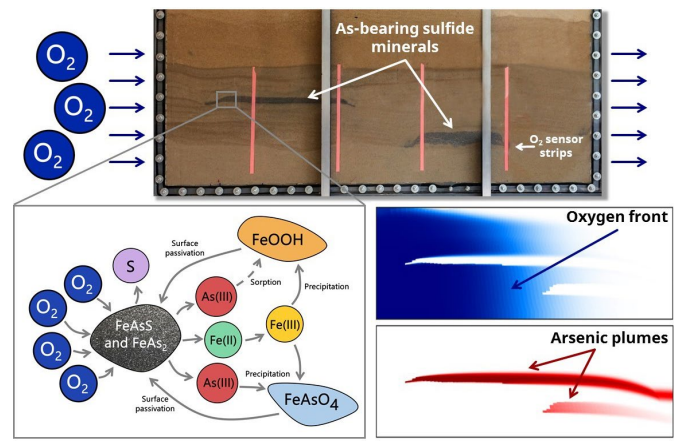

